
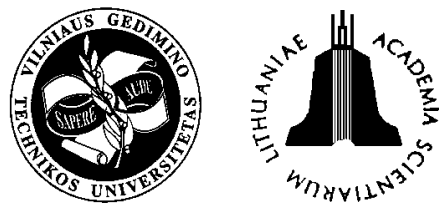

ISSN 1648-4142 print / ISSN 1648-3480 online TRANSPORT

www.transport.vtu.1t

\title{
MODELING PERFORMANCE OF RAILWAYS NODES AS INTERMODAL TERMINALS
}

\author{
Aidas Vasilis Vasiliauskas \\ Transport Research Institute, Vilnius Gediminas Technical University, Plytinès g. 27, \\ LT-10105 Vilnius, Lithuania.E-mail:aidasv@ti.vtu.lt
}

Received 15 January 2006; accepted 9 May 2006

\begin{abstract}
Present performance of railway transport sector is determined by two groups of factors. The first one relates to the changes of external economic environment of railway performance, while the second one deals with the internal changes in the railway transport sector. These factors determine priority directions of railway transport sector development. A good example of such development is implementation of intermodal services, which in turn foresee concept of integration of various logistics service providers.

In this paper assumption is made, that implementation of intermodal services as well as integration of various logistics services providers can not be reached without proper nodes on the multimodal transport networks. Therefore definition, urge and some key functions of intermodal terminal are discussed. Later theoretical model of such terminal performance is presented. The paper ends with conclusions about the meaning of intermodal terminal to the increase of quality level of railway transport sector performance.
\end{abstract}

Keywords: railway transport, transport node, intermodal transport, logistics integration.

\section{Introduction}

Present peculiarity of railway sector performance is determined by two groups of factors. The first one relates to the changes of external economic environment for railway performance and involves:

- instability of carried freight volumes;

- growth of strong competitive pressure from the side of other transport modes;

- development of system of intermodal carriages;

- involvement of country in formation of international transport corridors;

- need to reduce performance costs.

The second group of factors deals with the internal changes in the railway transport sector. This group involves:

- necessity to reorganize management structure;

- necessity to renew the equipment;

- increase of transport costs due to increase of fixed part of performance costs;

- reduction of grants (financial aid) [1].

Assessment of mentioned above factors allows identifying priority directions of railway transport sector development. In fact these directions deal with the solving of three types of tasks:
- improvement of organizational and management structure;

- implementation of technologies that helps to save resources;

- implementation and development of the new IT [2].

Notion should be made, that in most cases railway transport leg is just a part of total transport chain, the main feature of which is variety of different logistics actors making more or less input into assurance of services level required by the costumers. It follows that all these actors have the same goal - maintenance of the appropriate service level. Identity of their goals lay down a base for the possibility of their functional integration. Essence of integration - possibility of cooperation between different actors involved in the same transport chain and seeking common goals. This means that different actors putting their common efforts together can assure implementation of new technologies that help to save resources. A good example of such technology could be intermodal transportation where main leg is done by the railway transport [3, 4].

However, such a decision requires some appropriate places (nodes) in the network where connection between separate transport modes can be assured. Such places are known as intermodal terminals. 


\section{Intermodal terminals and their services}

Over the years shippers have been much more particular about their demand and the development seems to be towards even more advanced logistics services. The trend that the size of vehicles increases at the same time as the size of individual consignment decreases implies that a larger number of consignments have to be consolidated in each intermodal loading unit. It also necessitates efforts to unitize goods flow in order to tranship quickly and cheaply between transport modes [5]. Therefore a need for attractive transhipment operations occurs.

A terminal is a place where goods are transferred between any two or more freight transport modes. In this interface unit loads are collected, exchanged stored and/or distributed. Terminals are undisputedly an integral and crucial part of freight transport system. In some respects they are treated as infrastructure and as such a concern for authorities. But in other aspects they are treated as part of the freight transport operator's individual assets $[2,6]$.

The product of terminal is its service assortment. This assortment differs from terminal to terminal, however three central service groups can be defined. They are as follows: central terminal services, terminal related services and divert terminal services. Further these groups can be subdivided into some sub-services:

- Central terminal services: loading/unloading, direct transhipment without the storing, storage, cargo bundling/unbundling;

- Terminal related services: freight handling, collection/distribution of freight, physical transport of freight, freight monitoring;

- Diverted terminal services: manufacturing, renting/leasing/selling services, other services.

The aim of the terminal is to provide the customer with the best service assortment.

Every above mentioned operation is related to certain costs. That's why transportation costs increase markedly in the terminal point. Handling process is one of the most costly aspects of logistics channel performance and thus the objective is to reduce handling operations in the logistics chain to an absolute minimum [2-6].

However, very often one operator is not able to provide all these services on his own. Therefore concept of logistics integration emerges once again.

Presence of the node (intermodal terminals) on the network helps to bring the idea of logistics integration into reality.

In the nodes different variants of logistic schemes of fright movement are realized. The more complex one is a variant of intermodal transport, when two or more different transport modes are used. In this case material flow in the node is being shifted from one transport mode to another. As a consequence time of goods delivery increases. It is made up of a mandatory operations time and passive outage time:

$T_{p r}=M_{m e}+M_{g t}+M_{m r}+M_{j t}+M_{m 3}+M_{a t}+M_{m n}$,

where: $M_{m l}, M_{m r}, M_{m 3}, M_{m n}$ - time of operations taking place in the node (including passive outage); $M_{g t}$ - time of freight flow movement on the railway leg; $M_{j t}$ - time of freight flow movement on the maritime leg; $M_{a t}$ - time of freight flow movement on the road leg.

Because of this reason the operations taking place in the node must be well coordinated and automated. This in turn requires good understanding of terminal performance.

\section{Modeling of intermodal terminal performance}

Node (intermodal terminal) as a logistics system is a complex organizational structure which consists of separate elements (modules) joint in the united process of management of material and accompanying flows. This system is made of a whole of modules having clear functional dependence [7]. It represents different objects joint into particular systems according to various features:

- functional;

- informational, management;

- financial, legal.

For that reason node is recognized as logistical system having complex economic-organizational structure, which consists of elements joint into the common process of management of material and accompanying informational and document flows.

These three types of logistics chains are dependent on each other, because the time of the beginning of certain operation in a particular chain usually is determined by the end time of necessary operation in another chain. For example, material flow often can start moving only in case the necessary operations with the documents are completed.

Operations in different logistics chains can be presented in the form of vector-scalar components that form certain logistics chains:

$$
\left.\begin{array}{l}
a_{1} \rightarrow a_{2} \rightarrow \ldots \rightarrow a_{n} \\
u_{1} \rightarrow u_{2} \rightarrow \cdots \rightarrow u_{k} \\
g_{1} \rightarrow g_{2} \rightarrow \cdots \rightarrow g_{e}
\end{array}\right\} \text {, }
$$

where $a_{i} \rightarrow$ is an element of the material flow in the node (" $a_{i}$ " is a size of the flow, " $\rightarrow$ " is a vector showing direction of the flow movement, $i=1 \ldots n) ; u_{i} \rightarrow$ is an amount of information (" $u_{i}$ " is a size of information, 
“ $\rightarrow$ " direction of information flow, $i=1 \ldots k) ; g_{i} \rightarrow-$ element of the chain of preparation and distribution of documents related to material flow (" $g_{i}$ " - number or size of the document, " $\rightarrow$ " - direction of document transfer, $i=1$...e $)$.

Expression (2) determines functional-logistical structure of the node as a big technological system, in which time of material flow movement depends on many factors.

However, such expression points out only horizontal connections between elements in particular type of logistics chains. When index $i$ changes, the place of material flow as well as its time is also about to change, while size of the flow remains constant. By analogy, when index $i$ is about to change in case of $u$ and $g$, it means, that place and time of information and documentation generation, processing and transfer also change.

Among the analyzed processes there are functional interdependences that can be expressed by means of vertical relations “ $\downarrow$ ”.

Hence, expression (2) will obtain the following form:

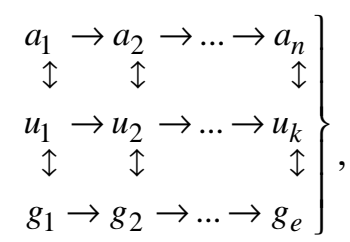

where “ $\downarrow$ ” are direct or backward relations among the technological processes with material, informational and document flows.

Expression (3) presents the structure of the node taking into account vertical relations and effect of one technological process on another. Such approach allows decomposition of a complex system (node) into separate elements as well as composition of separate elements into proper logistics chain according to their particular features.

In the process of composition into logistics chain, only those node elements are taken, which are treated as elements of node's system. In this case, whole node is presented as the composition of logistics chains.

Expressions presenting elements of the chains will obtain the following forms:

$$
\begin{aligned}
& A(t)=a_{1} \stackrel{t_{1}}{\longrightarrow} a_{2} \stackrel{t_{2}}{\longrightarrow} \ldots \stackrel{t_{n}}{\longrightarrow} a_{n}, \\
& U(t)=u_{1} \stackrel{t_{1}}{\longrightarrow} u_{2} \stackrel{t_{2}}{\longrightarrow} \ldots \stackrel{t_{n}}{\longrightarrow} u_{k}, \\
& G(t)=g_{1} \stackrel{t_{1}}{\longrightarrow} g_{2} \stackrel{t_{2}}{\longrightarrow} \ldots \stackrel{t_{n}}{\longrightarrow} g_{e},
\end{aligned}
$$

where sign " $\rightarrow$ " points out the shift from one element of the chain to another in time.

These expressions can also be written in the following form:

$$
\left.\begin{array}{l}
A(t)=\sum a_{i}\left(t_{i}\right) \\
U(t)=\sum u_{i}\left(t_{i}\right) \\
G(t)=\sum g_{i}\left(t_{i}\right)
\end{array}\right\} .
$$

Some transformations with the material flow take place when it is moving from one element of the node to another. Every single transformation stipulates certain material or time outlays.

Speaking about technological operations taking place in the node, we assume that time to perform particular operation is equal to $t_{t o}$. Also we have a time $t_{t l}$ which shows that sometimes there is a time required to wait for the next operation. Mentioned above components form time $t$ :

$$
t=\sum t_{t o}+\sum t_{t l} \text {. }
$$

Logistics chain sometimes is referred to be a constituent of the logistics aggregate. Taking into account that nodes are big systems, logistics aggregates must be presented in the tri-dimensional form. Every dimension affects time of movement of material flow in the aggregate and logistics chain.

Therefore logistics aggregate in the transport node is a sum of interrelated logistics chains and operations dealing with the processing of material flow and accompanying flow of information and documents. The latest two have a significant impact on the time of material flow movement.

It was already mentioned, that elements of logistics chains can be presented as a vector-scalar dimension, in which vector part shows direction of the flow movement. Also this part points out the most rational movement possibilities in the certain node. Also this component is related to time indexes, i.e. time of operation performance in every chain and waiting time for the next operation to be performed in horizontal $\left\{\stackrel{t_{i l}}{\longrightarrow}\right\}$ and vertical $\left\{\uparrow t_{i l} \downarrow t_{i l}\right\}$ direction.

Hence, vector-scalar model of node's logistics aggregate obtains the following form:

$$
\left.\begin{array}{l}
a_{0} \stackrel{\sum t_{0}}{\longrightarrow} a_{1} \stackrel{\sum t_{1}}{\longrightarrow} \ldots a_{i} \stackrel{\sum t_{i}}{\longrightarrow} \ldots a_{n} \stackrel{\sum t_{n}}{\longrightarrow} \\
\downarrow t_{n 0} \uparrow t_{n 0}^{\prime} \ldots \\
u_{0} \stackrel{\sum t_{0}^{\prime}}{\longrightarrow} u_{1} \stackrel{\sum t_{1}^{\prime}}{\longrightarrow} \ldots u_{i} \stackrel{\sum t_{i}^{\prime}}{\longrightarrow} \ldots u_{k} \stackrel{\sum t_{k}^{\prime}}{\longrightarrow} \\
\downarrow t_{n 0}^{\prime} i_{n 0}^{\prime \prime} \ldots \\
g_{0} \stackrel{\sum t_{0}^{\prime \prime}}{\longrightarrow} g_{1} \stackrel{\sum t_{1}^{\prime \prime}}{\longrightarrow} \ldots g_{i} \stackrel{\sum t_{i}^{\prime \prime}}{\longrightarrow} \ldots g_{l} \stackrel{\sum t_{l}^{\prime \prime}}{\longrightarrow}
\end{array}\right\} .
$$

Expression (9) presents vector-scalar model of logistics aggregate in case of one shipment being transported from shipper to consignee in the form of three interrelated logistics chains: material, in- 
formational and document. In this model scalar dimensions have the following expressions:

$$
\left.\begin{array}{l}
\sum_{i=1}^{n} a_{i}=A \\
\sum_{j=1}^{k} u_{j}=U \\
\sum_{t=1}^{l} g_{t}=G
\end{array}\right\},
$$

where $A$-size of the shipment; $U$-size of information related to shipment and $G$-amount of documents.

A time of performance of the operation in every technological line of aggregate also takes into account pauses because of vertical connections between operations in different logistics chains. Every logistics chain is tuned in to many different operations, which in the sense of time forms the following dimensions:

$$
\left.\begin{array}{l}
\sum_{i=1}^{n}\left(t_{i o}+t_{i l}\right)=T_{a} \\
\sum_{j=1}^{k}\left(t_{j o}^{\prime}+t_{j l}^{\prime}\right)=T_{u} \\
\sum_{\xi=1}^{l}\left(t_{\xi_{o}}^{\prime \prime}+t_{\xi_{l}}^{\prime \prime}\right)=T_{g}
\end{array}\right\},
$$

where $T_{a}$ - time of material flow dwelling in the aggregate; $T_{u}$-time of information processing and $T_{g}$ time of document processing.

Every logistics system consists of the sum of elements-modules, which have certain functional relations. In these modules, material, informational and document flows can unite and separate, change their size, parameters and intensity.

Every logistics chain in the node can be examined as a sequence:

$$
M_{1}, M_{2}, M_{3}, \ldots M_{n}
$$

where $n$ is a number of modules in the logistics chain.

Taking into account the structure of treated material flow, nodes can be presented as infinity of logistics aggregates involving all the logistics chains. Because of that, node can be analyzed as a system having the following expression:

$$
S=s\left\{A_{i j} ; x_{i j} ; y_{i j} ; z_{i j}\right\},
$$

where $A_{i j}-i$ logistics aggregate having $j$ functional destination; $X_{i j}$ - incoming material flow into $i$ logistics aggregate; $Y_{i j}$ - outgoing material flow from the aggregate $i ; Z_{i j}$-condition of the aggregate $i$.
Because flow in the node can be described by random dimensions, which at a certain time obtains particular values with the known degree of reliability, expression (13) can be rewritten as follows:

$$
S=s\left\{A_{i j} ; x_{i j}(t) ; y_{i j}(t) ; z_{i j}(t)\right\} .
$$

Examining separate logistics chains as a certain sum of logistics modules, it is necessary to highlight functional interoperability of the modules, which assure movement of material flow.

Shift from one state of the module to another can be expressed by the following equations, representing functional interoperability of the modules:

$$
\begin{aligned}
& z\left(t_{i=1}\right)=V\left[x\left(t_{i=1}\right), z\left(t_{i}\right)\right], \\
& z\left(t_{i=1}\right)=U\left[x\left(t_{i=1}\right), z\left(t_{i}\right), y\left(t_{i=1}\right)\right], \\
& z\left(t_{i=1}\right)=G\left[z\left(t_{i}\right), y\left(t_{i=1}\right)\right] .
\end{aligned}
$$

Operator $V$ describes access of the shipment to the module, while $U$ describes the end of processing of the first shipment and beginning of processing the second, and $G$-exit of the processed shipment from the module.

Load to the module $M(s)$ in the form of material flow can be set as $x_{1}, x_{2}, \ldots x_{n}$, in case of information flow $-u_{1}, u_{2}, \ldots u_{n}$, and in case of document flow $g_{1}, g_{2}, \ldots g_{n}$, and can be expressed in the following form:

$$
\left.\begin{array}{c}
x_{j}^{s}=\left(t, x_{1}, x_{2}, \ldots, x_{n}\right) \\
u_{j}^{s}=\left(t, u_{1}, u_{2}, \ldots, u_{n}\right) \\
g_{j}^{s}=\left(t, g_{1}, g_{2}, \ldots, g_{n}\right)
\end{array}\right\} .
$$

Module is described by the number of served channels, their potential (capacity) and reliability. State of the module is described by the number of shipments waiting to be served, number of shipments currently under processing and number of shipments waiting for an exit from the module.

Hence, from the equations (15-17) it follows, that state of the module can be described by vector $\beta^{s}$ :

$$
\beta^{s}=\left(t, d, \beta_{1}, \beta_{2}, \beta_{3}\right),
$$

where $t \in T, d$-number of the task being solved by the module; $\beta_{1}, \beta_{2}, \beta_{3}-$ number of shipments waiting to be served, number of shipments currently under processing and number of shipments processed by the module.

The Figure presents a view of the functioning of logistics module.

It is determined by incoming vector $I^{s}$, outgoing vector $Y^{s}$, work of the channel $m_{a p}$, number of places 
waiting to be processed $n_{l a}$ and number of places after processing $n_{p a}$.

In this case module becomes a system of mass attendance, whose functioning depends on the operators $V, U, G$ presented in the equations (15-17).

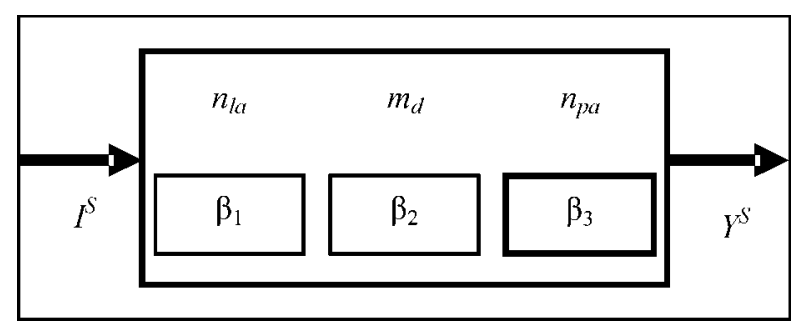

Common scheme of functioning of logistics module $M(s)$

\section{Conclusions}

1. Performance of railway transport sector is determined by factors related to the changes of external economic environment of railway performance and dealing with the internal changes in the railway transport sector. These factors direct future railway transport development, emphasizing the need to increase service quality level.

2. A good example of measures to increase service level is the development of intermodal transport services where main leg is done by railway transport. However, this decision requires integration of various logistics services providers acting in the same transport chain. Implementation of intermodal services as well as integration of various logistics services providers can not be reached without proper nodes - intermodal terminals.

3. Terminal is a place where goods are transferred between any two or more freight transport modes. The product of terminal is its service assortment. The aim of the terminal is to provide the customer with the best service assortment. Every terminal operation is related to certain costs. Handling process is one of the most costly aspects of logistics channel performance and thus the objective is to reduce handling operations in the logistics chain to an absolute minimum.

4. Terminal performance can be evaluated with the help of mass attendance theory. In this case performance of every terminal module can be determined by incoming vector $I^{s}$, outgoing vector $Y^{s}$, work of the channel $m_{a p}$, number of places waiting to be processed $n_{l a}$ and number of places after processing $n_{p a}$.

5. Performance technology of the node makes a crucial effect in implementing first and the last leg of intermodal transport chain (and determines competitiveness of the railway sector as a whole). Therefore in the light of instable freight flow volumes and competitiveness pressure from the side of other transport modes, assurance of efficient performance of these nodes becomes a vital necessity. In order to reach this objective, completely new methods, a good example of which is the development of integrated logistics management institutions (LC's, LC associations, transport-logistics complexes) are required.

\section{References}

1. Coyle, J. J. et all. Transportation. West Publishing Company, St. Paul, MN, USA, 1994.

2. Demkes, R. TRILOG - Europe End Report, TNO Inro, Delft, 1999.

3. Ballis, A.; Golias, J. Comparative evaluation of existing and innovative rail-road freight transport terminals. Transportation Research. Part A: Policy and Practice, Vol 36, No 7, p. 593-611.

4. Bithas, K.; Nijkamp, P. Critical factors for an effective and efficient multimodal freight transport network in Europe. Innovation, Vol 10, No 3, 1997, p. 243-258.

5. Konnings, J. W. Integrated centres for the transhipment, storage, collection and distribution of goods. Elsevier Science Ltd, London, 1996.

6. Terminet, New generation terminal and terminal-node concepts in Europe. Delft University of Technology, Delft, 1997.

7. Vasilis Vasiliauskas, A. Modeling of intermodal freight transportation network. Transport, Vol XVII, No 3, 2002, p. 117-121. 